\title{
Lung transplant: An emerging challenge in the ICU
}

\section{Trasplante pulmonar: un reto emergente en la $\mathrm{UCI}$}

\author{
J. Rello
}

Critical Care Department, Vall d'Hebron University Hospital, CIBERES \& VHIR, Universitat Autónoma de Barcelona, Spain

Lung transplantation shows good early results (1-year graft survival rate of $82.2 \%)$. Moreover, survival over a 5 -year period is still high $(50.5 \%) .^{1}$ Lung transplantation is associated with substantial risks and severe complications that account for early mortality in the postoperative period (mainly primary graft failure, infection, bleeding and airways complications). ${ }^{2}$ However, long-term survival is determined primarily by the development of bronchiolitis obliterans syndrome (BOS), the effects of which may be manifested as progressive respiratory failure or by an

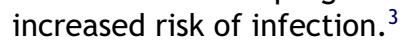

In 2011, 235 lung transplants were conducted in Spain, being a big challenge in the postoperative period in 7 hospitals. Two physicians of each of these institutions, plus a coordinator discussed current challenges in a meeting in Santiago in October 2011 and launched a research cooperative network (PLUTO network). Some of the expositions will be reported in this series as reviews and original articles.

This subgroup of immunosupressed patients is unique given that the transplanted organ is in constant direct contact with the environment and is deprived of its lymphatic drainage and nerve supply, rendering it unique susceptibility to infections. Even more, it has been suggested that over-immunosupression in lung-transplanted patients is real and is detectable in patients with infectious complications. ${ }^{4}$ Because the number of lung transplants has been increasing over the years, and has been accompanied by higher survival rates, we may anticipate that the number of lung transplanted patients readmitted to ICU will continue to rise in the forthcoming years. The study of this sub-population is, thereby, of extreme relevance and actuality. ${ }^{5-8}$ This issue of Medicina Intensiva begins

E-mail address: jrello@crips.es a series of manuscripts that examine various aspects of the acute phase of lung transplantation. Medical treatment greatly differs according to diagnosis. While rejection is based on an increase in the immunosuppression; infections call for antibiotic treatment, being worthy to evaluate a potential immunosuppression decrease. So far, no reliable methods are available to anticipate diagnosis in lung transplant patients. Specific aspects of immunosuppression and their immunologic implications are discussed in detail in this series.

Acute graft rejection and primary graft dysfunction are cornerstones of the post-transplant acute respiratory failure (ARF). Albeit the low incidence in the immediate postoperative period, it has a far-reaching impact on the clinical outcome of these patients. Acute rejection early diagnosis and proper treatment usually leads to a favorable response, nevertheless, its diagnosis still depends on invasive transbronchial biopsies for final confirmation. Therefore, new and less invasive methods that prompt early diagnosis are needed. Recently, advances in identifying humoral rejection, ${ }^{9}$ treated with plasmapheresis, immunoglobulines and monoclonal antibodies represent an area of uncertainty. Need of Extracorporeal membrane oxygenation and potential use of this technique as a bridge to transplantation is important and have to be used in all groups with large lung transplant programs.

Apart from graft rejection, another large group of complications that display acute respiratory failure are infections, and they are clinically difficult to distinguish from acute rejection. $30 \%$ of lung transplant patients develop an infectious complication and $10 \%$ present acute graft rejection. ${ }^{10} \mathrm{~A}$ multicenter study has analyzed the incidence and the etiology of pneumonia in lung transplant (72 episodes out of 100 transplants per year): $80 \%$ were of bacterial cause, $14 \%$ fungal and $10 \%$ viral. ${ }^{11}$ Other pneumonia 
series in lung transplant had similar results. ${ }^{12,13}$ For this reason, antifungal prophylaxis is a challenge.

The ventilator-associated pneumonia (VAP) is a common clinical entity with prognostic relevance in critically ill patients. The study "The Extended Prevalence of Infection in Intensive Care (EPIC II) clarified that $51 \%$ of patients admitted in the ICU are infected, and that $64 \%$ of those infections have a respiratory origin. ${ }^{14}$ These patients present higher morbidity and mortality, and prolonged stay in ICU. Risk factors and appropriate clinical management are thereby key stones that may determine VAP evolution, ${ }^{15,16}$ making its study of major relevance. With the technology available today, biomarkers could play a crucial role in early diagnosis, monitoring and treatment of such infectiousinflammatory processes.

Many efforts have to be done to increase the number of lungs for transplantation. Due to the shortage, newer strategies, such as ex vivo perfusion and use of suboptimal lung organs are used to overcome the shortage. Another interesting experience is the use of lungs obtained from donors with stopped heart. Ultimately, fellows and residents have to be implicated in the culture of transplantation, both in organ donation as well in the care of the lung organ recipient. Objectives and strategies of learning to reach this goal will be detailed in this series.

\section{Conflict of interests}

Jordi Rello received honoraria as member of the Speakers bureau and consultancies for Astellas.

\section{Acknowledgement}

Supported in part by CIBERES-PCI pneumonia, AGAUR and FISS $11 / 1122$.

\section{References}

1. Wolfea RA, Merionb RM, Roysa EC, Porta FK. Trends in organ donation and transplantation in the United States, 1998-2007. Am J Transplant. 2009;9:869-78.
2. Harringer W, Wiebe K, Struber M, Franke U, Niedermeyer J, Fabel $\mathrm{H}$, et al. Lung transplantation: 10-year experience. Eur J Cardiothorac Surg. 1999;16:546-54.

3. Boehler A, Kesten S, Wedere W, Speich R. Bronchiolitis obliterans after lung transplantation: a review. Chest. 1998;114:1411-26.

4. Kowalski RJ, Post DR, Mannon RB, Sebastian A, Wright HI, Sigle $G$, et al. Assessing relative risks of infection and rejection: a meta-analysis using an immune function assay. Transplantation. 2006;82:663-8.

5. Cohen J, Singer P, Raviv Y, Bakal I, Shitrit D, Shaul Lev S, et al. Outcome of lung transplant recipients requiring readmission to the intensive care unit. J Heart Lung Transplant. 2011;30: 54-8.

6. González-Castro A, Suberviola B, Llorca J, González-Mansilla C, Ortiz-Melón F, Miñambres $\mathrm{E}$. Prognosis factors in lung transplant recipients readmitted to the intensive care unit. Transplant Proc. 2007;39:2420-1.

7. Hadjiliadis H, Steele MP, Govert JA, Davis D, Palmer SM. Outcome of lung transplant patients admitted to the medical ICU. Chest. 2004;125:1040-5.

8. Pietrantoni C, Minai OA, Yu NC, Maurer JR, Haug MT, Mehta AC, et al. Respiratory failure and sepsis are the major causes of ICU admissions and mortality in survivors of lung transplant. Chest. 2003;123:504-9.

9. Allan R. Antibody-mediated rejection in lung transplantation: myth or reality? J Heart Lung Transplant. 2010;29: 395-400.

10. Sacanell J. Lung transplantation. Analyses of 129 cases (Abstract). Intensive Care Med. 2010;36:S147.

11. Aguilar-Guisado M, Gavaldà J, Ussetti $P$, Ramos A, Morales $P$, Blanes $M$, et al. Pneumonia after lung trasnplantation in the RESITRA cohort. Am J Transplant. 2007;7:1989-96.

12. Gavaldà J, Roman A. Infection in lung transplantation. Enferm Infecc Microbiol Clin. 2007;25:639-49.

13. Campos S, Caramori M, Teixeira R, Afonso J, Carraro R, Strabelli $T$, et al. Bacterial and fungal pneumonias after lung transplantation. Transplan Proceed. 2008;40:822-4.

14. Vincent JL, Rello J, Marshall J, Silva E, Anzueto A, Martin CD, et al. International study of prevalence and outcomes of infection in ICU. JAMA. 2009;302:232318-28.

15. Rello J, Chastre J, Cornaglia G, Masterton R. A European care bundle for management of VAP. J Crit Care. 2011;26:3-10.

16. Rello J, Ulldemolins M, Lisboa T, Koulenti D, Mañez R, Martin-Loeches I, et al. Determinants of choice and prescription in empiric antibiotic therapy for HAP/VAP. Eur Respir J. 2011;37:1332-9. 